\title{
Genetic variation in the human vitamin D receptor is associated with muscle strength, fat mass and body weight in Swedish women
}

Elin Grundberg, Helena Brändström, Eva L Ribom ${ }^{1}$, Östen Ljunggren, Hans Mallmin ${ }^{1}$ and Andreas Kindmark Department of Medical Sciences, Uppsala University Hospital, SE-75185 Uppsala, Sweden and ${ }^{1}$ Department of Surgical Sciences, Section of Orthopaedics, Uppsala University Hospital, SE-75185 Uppsala, Sweden

(Correspondence should be addressed to E Grundberg; Email: Elin.Grundberg@medsci.uu.se)

\begin{abstract}
Objective: Bone mineral density (BMD) is under strong genetic control and a number of candidate genes have been associated with BMD. Both muscle strength and body weight are considered to be important predictors of BMD but far less is known about the genes affecting muscle strength and fat mass. The purpose of this study was to investigate the poly adenosine (A) repeat and the BsmI SNP in the vitamin D receptor (VDR) in relation to muscle strength and body composition in healthy women.

Design: A population-based study of 175 healthy women aged 20-39 years was used.

Methods: The polymorphic regions in the VDR gene (the poly A repeat and the BsmI SNP) were amplified by PCR. Body mass measurements (fat mass, lean mass, body weight and body mass index) and muscle strength (quadriceps, hamstring and grip strength) were evaluated.

Results: Individuals with shorter poly A repeat, ss and/or absence of the linked BsmI restriction site (BB) have higher hamstring strength (ss vs LL, $P=0.02$ ), body weight (ss vs LL, $P=0.049$ ) and fat mass (ss vs LL, $P=0.04$ ) compared with women with a longer poly A repeat (LL) and/or the presence of the linked BsmI restriction site $(\mathrm{bb})$.

Conclusions: Genetic variation in the VDR is correlated with muscle strength, fat mass and body weight in premenopausal women. Further functional studies on the poly A microsatellite are needed to elucidate whether this is the functionally relevant locus or if the polymorphism is in linkage disequilibrium with a functional variant in a closely situated gene further downstream of the VDR $3^{\prime} \mathrm{UTR}$.
\end{abstract}

European Journal of Endocrinology 150 323-328

\section{Introduction}

Body composition, including bone mineral content, fat mass and lean mass, is known to be under strong genetic control with a suggested heritability of fat mass and lean mass of $52-57 \%$ (1). Several candidate genes have been identified that may contribute to bone mineral density (BMD), far less is known about genes affecting muscle strength and fat mass. The gene for the vitamin $D$ receptor (VDR) is one of the genes that has been most extensively studied in relation to $\mathrm{BMD}$, due to the important role of vitamin D in bone metabolism (reviewed in 2). A functional genetic polymorphism in the VDR could be involved in other tissues that respond to vitamin D, such as muscle cells and adipocytes. It has been demonstrated that skeletal muscle is a target organ for vitamin $\mathrm{D}$, and that vitamin $\mathrm{D}$ metabolites directly affect muscle cell metabolism through various pathways (3). Also, vitamin D deficiency is associated with muscle weakness $(3,4)$. Moreover, it has been demonstrated that vitamin D stimulates the differentiation of preadipocytes to adipocytes in the $\mathrm{OB} 17$ cell line (5). Some studies have also suggested a relationship between body size, as measured by body length and weight, and allelic variations of the VDR gene (6-8), indicating that VDR genotype may function as a determinant of body composition.

Thus far, the association of VDR polymorphisms and muscle strength in a population-based study has not been studied and only Geusens et al. (9) have reported a correlation between VDR alleles and muscle strength in a study of non-obese, elderly women. The association studies made on the VDR gene have mainly focused on the different single nucleotide polymorphisms (SNPs) 
rather than on the poly A microsatellite at the VDR $3^{\prime}$ UTR - a region that has been postulated to be important for mRNA stability (reviewed in 10).

This study examines the relationship between a poly adenosine (A)-repeat and a BsmI SNP in the gene for the VDR on variation in muscle strength, fat mass, lean mass, body weight and body mass index (BMI) in a Swedish female population-based cohort.

\section{Subjects and methods}

\section{Subjects}

The study cohort consisted of a total of 175 women, aged 20-39 years, randomly selected from the population registry of the county of Uppsala. In all, 347 women were randomly selected and invited by mail to participate. Of the invited women, 172 did not participate and were excluded, of these nine were pregnant, 26 had moved, 98 did not contact the research centre and were not reached despite repeated letters, and 39 were not interested in participating. In total 175 (50\%) of the invited women attended the investigation and were included. Of these 175 individuals, 169 were examined for left quadriceps and hamstring strength, 172 for right quadriceps and hamstring strength, 171 for left handgrip strength and 172 for right handgrip strength. This resulted in a total of 169 women all examined for bilateral quadriceps strength, bilateral hamstring strength and bilateral handgrip strength. The main reason for the absence of muscle strength data was instrument failure. Blood samples for DNA extraction were obtained from 168 individuals and the samples were stored at $-20^{\circ} \mathrm{C}$ until processing and analysis. Subjects answered a questionnaire regarding, for example, medications, menstrual status, oral contraceptives and number of children. To increase the possibility of having a genetically homogenous cohort individuals with non-Swedish origin were excluded, resulting in a total of 153 individuals included in the genetic association study. The study was approved by the local ethics committee (Dnr 991007).

\section{Muscle strength measurements}

Handgrip strength was measured by a JAMAR hydraulic hand dynamometer (5030J1, Jackson, MI, USA) and expressed in kg. Measurements were made three times on both hands and the mean values from the right and left hand were used in the comparison. Isokinetic knee-flexion and extension strength was measured by a Cybex II dynamometer (Lumex, Corp., Bay Shore, NY, USA) with a modified level arm (Aero Technical Corp., Stockholm, Sweden and devised by Knutsson and Litton) and an examination table (Alfex). Muscle strength was expressed in Newton metres (Nm) and calibration of the Cybex II has been described in detail elsewhere (11). The subjects were strapped in a sitting position with adjustable belts around the thigh and chest. The axis of the level arm of the dynamometer was adjusted after the axis of the knee joint. The range of motion measured was between full extension $\left(0^{\circ}\right)$ to $90^{\circ}$ of knee flexion and back to full extension. The angular velocity used was $90 \%$ s. Three measurements were performed and the best values for flexion and extension were used to calculate the mean values for left and right leg. Moreover, mean values for left and right flexion strength and for left and right extension strength were used in the association study.

\section{Measurements of body composition, height and weight}

Fat mass and lean mass were measured by dual-energy X-ray absorptiometry (DXA), using a DPX-IQ scan (Lunar Corp., Madison, WI, USA) and expressed in $\mathrm{kg}$. The stability of the DPX-IQ equipment was checked every morning using a phantom. The long-term precision for L2-L4 BMD, expressed as the coefficient of variance was determined by daily measurements of a lumbar spine phantom and was less than $0.5 \%$ during the study period. Height and weight were assessed at a clinical examination by Holtain stadiometer (Holtain Ltd, Crosswell, UK) and digital scale (EKS) prior to the DXA scanning.

\section{DNA analysis}

Genomic DNA was extracted from leukocytes from $3 \mathrm{ml}$ EDTA blood using a Wizard Genomic DNA purification kit (Promega, Madison, WI, USA), typically yielding approximately 50-75 $\mu \mathrm{g}$ genomic DNA/sample.

The VDR poly A microsatellite in the 3'UTR and the BsmI SNP in intron 8 were amplified by PCR using primers and conditions as previously reported (12).

\section{Statistical analysis}

All statistical calculations were performed using STATISTIKA software (StatSoft Inc., Tulsa, OK, USA) by ANOVA comparing the means for the differences of the continuous variables between genotype groups. Multiple regression analysis was performed to correct for confounding factors, thus the genotype information was entered into the model along with age, fat mass and lean mass. The $\mathrm{R}^{2}$ value is the coefficient of determination and explains the model's relative contribution to the variation of muscle strength. Hardy-Weinberg equilibrium at the different loci was tested by exact tests and the VDR polymorphisms were analysed for linkage disequilibrium by the Fisher's test, using the GENEPOP web version 3.1c (http://wbiomed.curtin. edu.au/genepop).

\section{Results}

The number of poly A repeats in the VDR gene varied between 11 and 23 (Fig. 1), as determined after 


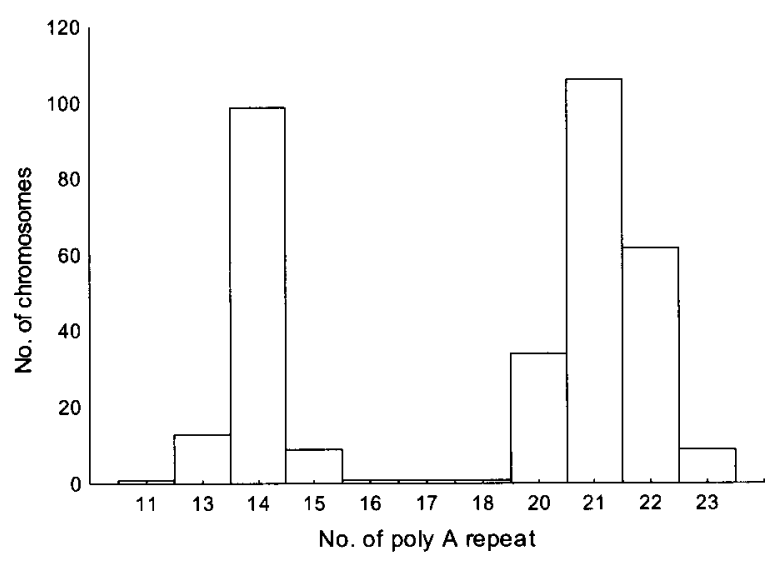

Figure 1 Frequency distribution of the poly A microsatellite in the VDR gene and each of the 168 women is represented by her two alleles. Alleles containing $<18$ repeats are denoted short (s) and alleles containing $\geq 18$ repeats are denoted as long $(L)$, according to the naturally occurring bimodal distribution of the poly $A$ repeat

sequencing of representative gene fragments (data not shown). The genotypes with $<18$ repeats were denoted short (s) and genotypes with $\geq 18$ repeats were denoted long (L). This cut-off corresponds to the naturally occurring bimodal distribution of the genotypes in our study population (Fig. 1). The genotypes and frequencies for the BsmI SNP were: 14\% BB (absence of the BsmI restriction site on both alleles), $48 \% \mathrm{Bb}$ (heterozygous for the restriction site) and $38 \%$ bb (presence of the restriction site on both alleles). For the poly $A$ microsatellite, $14 \%$ were homozygous for the short allele (ss), 45\% were heterozygous (sL) and $41 \%$ were homozygous for the long allele (LL). The frequency distribution of the poly A and BsmI genotypes were similar to frequencies reported in other Caucasian study groups (13) and both polymorphisms were in HardyWeinberg equilibrium. Furthermore, a strong linkage was found between the $\mathrm{s}$ and $\mathrm{B}$ alleles $\left(\mathrm{Chi}^{2}=291\right.$, $P<0.0001$ ) (Table 1). Clinical characteristics of the study population are presented in Table 2 .

\section{VDR genotype and muscle strength}

A significant association was found between VDR genotype and muscle strength in the study population. Women carrying the poly A genotype ss and/or the linked BsmI genotype $\mathrm{BB}$ had higher hamstring strength as compared with individuals in the LL and bb genotype group (ss $62.8 \pm 9.0 \mathrm{Nm}$ vs LL $55.6 \pm 10.2 \mathrm{Nm}, P$ value 0.02 ; $\mathrm{BB} 62.1 \pm 8.7 \mathrm{Nm}$ vs bb 55.5 $\pm 10.2 \mathrm{Nm}, P$ value 0.03; ANOVA and Fisher's LSD) (Fig. 2). To investigate whether the VDR genotype effect on muscle strength was modified by confounding factors, age, fat mass and lean mass were entered into a multiple regression model with the genotype information (Table 3 ). The results demonstrated borderline significant correlations of the BsmI $(P=0.05)$ and poly A $(P=0.06)$ genotypes and hamstring strength
Table 1 Contingency table for genotypic disequilibrium. The linkage disequilibrium was tested by the Fisher's test using the GENEPOP web version 3.Ic.

\begin{tabular}{lrrrr}
\hline Locus & BB & Bb & bb & Total \\
\hline Poly A 11.18 & 0 & 1 & 0 & 1 \\
Poly A 13.13 & 3 & 0 & 0 & 3 \\
Poly A 13.15 & 1 & 0 & 0 & 1 \\
Poly A 13.16 & 1 & 0 & 0 & 1 \\
Poly A 13.20 & 0 & 1 & 0 & 1 \\
Poly A 13.21 & 0 & 1 & 0 & 1 \\
Poly A 13.22 & 0 & 1 & 0 & 1 \\
Poly A 14.14 & 15 & 0 & 0 & 15 \\
Poly A 14.20 & 0 & 13 & 0 & 13 \\
Poly A 14.21 & 0 & 24 & 0 & 24 \\
Poly A 14.22 & 0 & 16 & 0 & 16 \\
Poly A 14.23 & 0 & 6 & 0 & 6 \\
Poly A 15.15 & 1 & 0 & 0 & 1 \\
Poly A 15.17 & 0 & 1 & 0 & 3 \\
Poly A 15.21 & 0 & 3 & 0 & 2 \\
Poly A 15.22 & 0 & 2 & 0 & 9 \\
Poly A 20.20 & 0 & 1 & 8 & 1 \\
Poly A 20.22 & 0 & 0 & 1 & 34 \\
Poly A 21.21 & 0 & 1 & 33 & 153 \\
Poly A 21.22 & 0 & 1 & 1 & \\
Poly A 22.22 & 0 & 1 & 59 & \\
Total & 21 & 73 & & \\
\hline
\end{tabular}

$\mathrm{Chi}^{2}=291 ; P<0.0001$.

when taking age, fat mass and lean mass into account. No significant associations were found between VDR genotypes and quadriceps strength and between VDR genotypes and handgrip strength.

\section{VDR genotype and body composition}

The clinical characteristics of the poly A and BsmI genotype groups are shown in Table 4 . Body weight and fat mass were higher in women carrying the poly A genotype ss compared with individuals in the LL genotype group (ss $69.4 \pm 10.4 \mathrm{~kg}$ vs LL $64.2 \pm 8.6 \mathrm{~kg}, P$ value 0.049 ; ss $23.7 \pm 7.8 \mathrm{~kg}$ vs $\mathrm{LL} 19.9 \pm 6.9 \mathrm{~kg}, P$ value 0.04). Similar results were seen concerning the effect of VDR BsmI genotype on body weight and fat mass (BB $69.1 \pm 10.5 \mathrm{~kg}$ vs bb $64.4 \pm 8.7 \mathrm{~kg}, P$ value 0.08 ; $\mathrm{BB} 23.9 \pm 7.9 \mathrm{~kg}$ vs bb $20.1 \pm 7.0 \mathrm{~kg}, P$ value 0.049$)$.

Table 2 Subject characteristics. Values are means \pm S.D. where applicable.

\begin{tabular}{lcc}
\hline Characteristics & $\boldsymbol{n}$ & Study cohort \\
\hline Age (years) & 153 & $29.6 \pm 5.9$ \\
Height $(\mathrm{cm})$ & 153 & $167.9 \pm 5.8$ \\
Weight $(\mathrm{kg})$ & 153 & $66.0 \pm 10.6$ \\
Grip strength (Nm) & 153 & $33.5 \pm 4.8$ \\
Quardriceps strength (Nm) & 153 & $118.2 \pm 19.8$ \\
Hamstring strength (Nm) & 153 & $57.8 \pm 12.0$ \\
Age of menarche (year) & 140 & $12.8 \pm 1.4$ \\
Use of oral contraceptives (\%) & 146 & 82.8 \\
$>2$ children (\%) & 146 & 6.2 \\
\hline
\end{tabular}



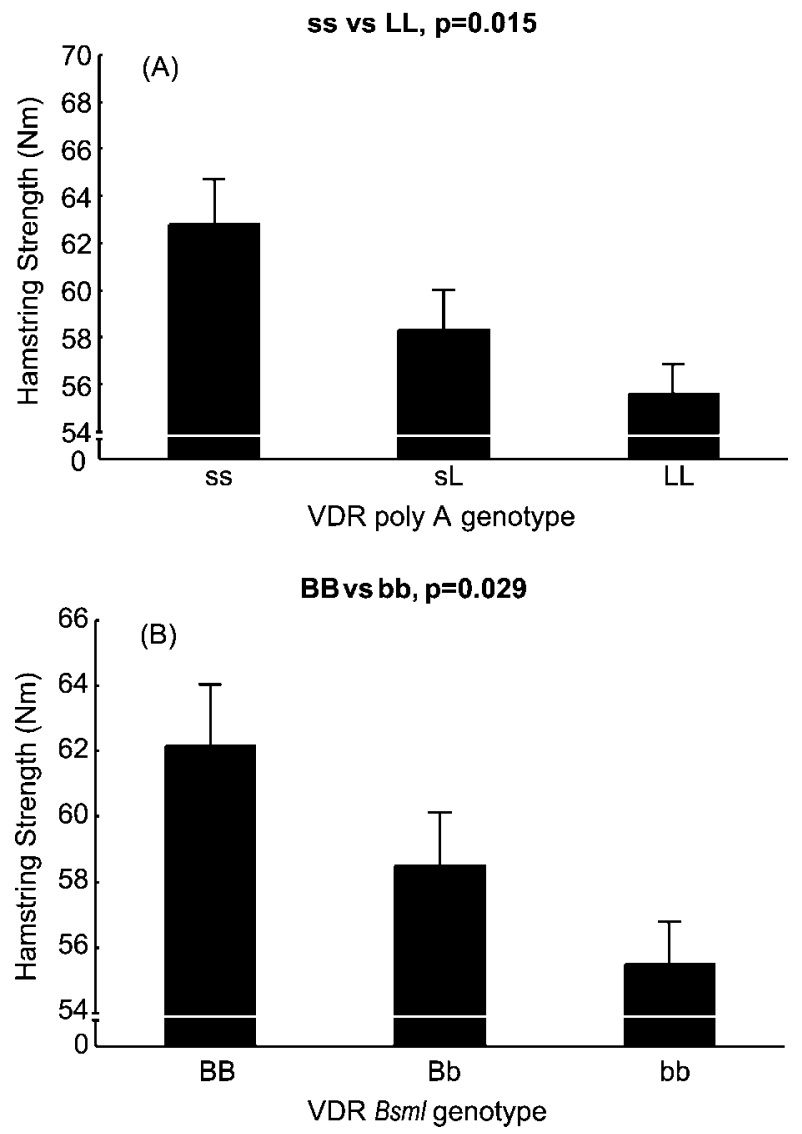

Figure 2 Association of muscle strength with VDR genotype. Isokinetic knee-flexion strength was measured by a Cybex II dynamometer and expressed in $\mathrm{Nm}$ in a study cohort consisting of 153 healthy young women. Data are presented as means \pm S.E. for the genotypic subgroups of the poly A microsatellite and the linked Bsml SNP in the VDR gene. Statistical analyses were performed using STATISTIKA software and $P<0.05$ was considered as statistically significant. The frequency distribution of the poly $\mathrm{A}$ was ss $15 \%(n=22)$, sL $44 \%(n=68)$ and LL $41 \%(n=63)$. The BB genotype group consists of $21(14 \%)$ individuals, group Bb of $73(48 \%)$ individuals and the bb genotype group of $59(38 \%)$ individuals. (A) Effect of the poly $A$ genotypes $S s, S L$ and $L L$ on hamstring strength and $(B)$ effect of the Bsml genotypes $\mathrm{BB}, \mathrm{Bb}$ and $\mathrm{bb}$ on hamstring strength.

The same trend was observed regarding the effect of the

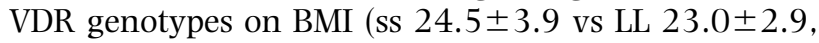
$P$ value 0.08 ; $\mathrm{BB} 24.5 \pm 3.9$ vs bb $23.0 \pm 3.0, P$ value 0.09).

\section{Discussion}

In this report we have demonstrated associations of the VDR genotype with muscle strength in a female population-based study. Our results show that individuals in the ss genotype group had $11.5 \%$ higher muscle strength, as measured at the hamstrings, compared with women in the LL genotype group. Thus, the results showed a strong association of VDR genotype with hamstring strength, and a similar pattern for
Table 3 Multiple regression analyses for hamstring strength vs age, fat mass, lean mass and VDR genotype groups.

\begin{tabular}{lcc}
\hline Prediction model & $\boldsymbol{\beta}$-coefficient & $\boldsymbol{P}$ value \\
\hline VDR genotype† & & \\
SL & -0.13 & 0.15 \\
LL & -0.18 & 0.06 \\
Age & -0.20 & $0.002^{*}$ \\
Fat mass & 0.18 & $0.009^{*}$ \\
Lean mass & 0.55 & $<0.0001^{* \star *}$ \\
Model R & 0.43 & \\
(adjusted) & & \\
VDR genotypeł & & \\
bB & -0.14 & 0.14 \\
bb & -0.18 & 0.05 \\
Age & -0.20 & $0.002^{*}$ \\
Fat mass & 0.18 & $0.01^{*}$ \\
Lean mass & 0.55 & $<0.0001^{* \star *}$ \\
Model R2 & 0.43 & \\
(adjusted) & & \\
\hline
\end{tabular}

${ }^{\dagger}$ VDR poly $A$ sL and LL genotype in relation to the ss genotype; ${ }^{\ddagger}$ VDR $B s m / b B$ and bb genotype in relation to the BB genotype.

${ }^{\star} P<0.05 ;{ }^{* \star \star} P<0.001$

the effect on quadriceps. This is in line with the quadriceps being the major load-bearing muscle during normal activity, and which may therefore be more susceptible to environmental factors, i.e. exercise, resulting in a proportionately larger genetic component of hamstring strength than of quadriceps strength. Vitamin D deficiency is associated with muscle weakness and low muscle strength is an important risk factor for development of osteoporotic fractures (14). VDR has been found in human skeletal muscle cells and affects muscle cell metabolism by binding to vitamin D metabolites $(14,15)$. We have previously shown an association between VDR genotype and BMD, where individuals in the ss genotype group had significantly higher lumbar spine BMD compared with the LL genotype group (12). Taken together, this correlates well with muscle strength being under genetic control and associated with BMD.

To our knowledge, this is the first study that demonstrates a significant association of VDR alleles and muscle strength in a population-based cohort of premenopausal women. However, Geusens et al. (9) have reported a correlation of a VDR polymorphism and muscle strength in postmenopausal women but the significance was only found in the subgroup of non-obese $\left(\mathrm{BMI}<30 \mathrm{~kg} / \mathrm{m}^{2}\right)$ women. In contrast, the effect of VDR polymorphisms on muscle strength in our study was shown in the entire cohort. However, exclusion of obese subjects (BMI $\left.>30 \mathrm{~kg} / \mathrm{m}^{2}, n=6\right)$ showed stronger correlations of VDR polymorphisms with muscle strength (data not shown), which is in agreement with Geusens et al. (9).

In addition, we found an association of the VDR genotype with body composition. Our results showed that individuals with short poly A repeat (ss) and/or absence of the linked BsmI restriction site on both alleles (BB) 
Table 4 Clinical features of the study population in relation to VDR poly A and Bsml genotype. Values are means \pm S.D.

\begin{tabular}{lrccccccc}
\hline Characteristics & LL $(n=63)$ & $\mathbf{s L}(n=68)$ & $\mathbf{s s}(n=22)$ & $\boldsymbol{P}_{\text {value }}$ & $\mathbf{b b}(n=59)$ & $\mathbf{B b}(n=73)$ & BB $_{(n=21)}$ & $\boldsymbol{P}$ value $^{2}$ \\
\hline Weight $(\mathrm{kg})$ & $64.2 \pm 8.6$ & $66.4 \pm 12.1$ & $69.4 \pm 10.4$ & $<0.05^{\star}$ & $64.4 \pm 8.7$ & $66.3 \pm 11.9$ & $69.1 \pm 10.5$ & 0.08 \\
Height $(\mathrm{cm})$ & $167.1 \pm 4.8$ & $168.5 \pm 6.3$ & $168.6 \pm 6.5$ & 0.30 & $167.2 \pm 4.9$ & $168.5 \pm 6.2$ & $168.2 \pm 6.3$ & 0.51 \\
BMl $\left(\mathrm{kg} / \mathrm{m}^{2}\right)$ & $23.0 \pm 2.9$ & $23.3 \pm 3.5$ & $24.5 \pm 3.9$ & 0.07 & $23.0 \pm 3.0$ & $23.3 \pm 3.5$ & $24.5 \pm 3.9$ & 0.09 \\
Fat mass $(\mathrm{kg})$ & $19.9 \pm 6.9$ & $20.9 \pm 8.1$ & $23.7 \pm 7.8$ & $<0.05^{\star}$ & $20.1 \pm 7.0$ & $20.7 \pm 8.0$ & $23.9 \pm 7.9$ & $<0.05^{\star}$ \\
Lean mass $(\mathrm{kg})$ & $41.1 \pm 4.0$ & $42.2 \pm 5.2$ & $42.5 \pm 4.9$ & 0.25 & $41.2 \pm 4.1$ & $42.3 \pm 5.2$ & $41.9 \pm 4.4$ & 0.50 \\
\hline
\end{tabular}

${ }^{1}$ ss genotype group vs LL genotype; ${ }^{2} \mathrm{BB}$ genotype group vs bb genotype. ${ }^{*} P<0.05$.

have significantly higher body weight and fat mass. Previous studies have demonstrated a relationship between body size in children and allelic variants of the VDR gene, with which our findings agree. One study in 589 French children reported that at 2 years of age body weight was greater in girls with the BB genotype compared with individuals in the bb genotype group (6). Furthermore, a retrospective study in infant health records of 66 postmenopausal British women showed that those with the BB genotype had $7 \%$ higher weight than those with the bb genotype at 1 year of age (7). Another study of 309 unrelated French subjects with early onset type 2 diabetes suggests that variations in the VDR gene are associated with susceptibility to obesity (16). However, the pathophysiological mechanisms of these associations remain unexplained. A direct effect of vitamin D on adipocyte differentiation and metabolism is a possible mechanism, as VDR is expressed in preadipocytes (17). Dace et al. (5) showed that calcitriol stimulates the differentiation of preadipocytes to adipocytes in the $\mathrm{OB} 17$ cell line, which provides arguments for a probable role of vitamin $\mathrm{D}$ in adipose differentiation by binding to the VDR.

The molecular mechanisms behind the genotype/ phenotype associations observed for these polymorphisms in the VDR gene are still unclear. The BsmI SNPs, situated in intron 8, are non-coding and do not change the amino acid sequence of the VDR protein and, as far as we know, the BsmI SNP is non-functional. However, we and others have shown that the BsmI $\mathrm{B}$ allele is in linkage disequilibrium with the poly A $\mathrm{s}$ allele in the VDR $3^{\prime}$ UTR. There are several studies trying to identify whether this poly A microsatellite affects mRNA stability (18), but results have been inconclusive (19). A possible hypothesis is that a long poly A repeat is less stable and translated less efficiently into VDR protein, resulting in a decreased response to vitamin $\mathrm{D}$ and thus an inhibition of muscle cell and adipocyte differentiations. This is in line with Carling et al. (20) who have showed that B alleles are associated with higher VDR mRNA levels in a study of patients with sporadic primary hyperparathyroidism. However, further functional studies on the poly A microsatellite are needed to elucidate whether this is the functionally relevant locus or if the polymorphism is in linkage disequilibrium with a functional variant in a closely situated gene further downstream of the VDR $3^{\prime}$ UTR.

This is, to our knowledge, the first study that demonstrates a significant association of the VDR poly A microsatellite and the linked BsmI SNP to muscle strength and body composition in premenopausal women. In conclusion, further studies are required to elucidate the molecular mechanism behind the genotype/phenotype associations and to investigate whether the VDR $3^{\prime} \mathrm{UTR}$ poly A microsatellite has a functional role.

\section{Acknowledgements}

We thank Anna-Lena Johansson, Ann-Charlotte Adolfsson, Marja Gustavsson, Lena Lundberg and Katarina Nisser for skilful technical assistance. This work was supported by grants from the Swedish Society for Medicine.

\section{References}

1 Deng HW, Lai DB, Conway T, Li J, Xu FH, Davies KM et al. Characterization of genetic and lifestyle factors for determining variation in body mass index, fat mass, percentage of fat mass, and lean mass. Journal of Clinical Densitometry 2001 4 353-361.

2 Uitterlinden AG, Fang Y, Bergink AP, van Meurs JB, van Leeuwen HP \& Pols HA. The role of vitamin D receptor gene polymorphisms in bone biology. Molecular and Cellular Endocrinology 2002 $19715-21$.

3 Janssen HC, Samson MM \& Verhaar HJ. Vitamin D deficiency, muscle function, and falls in elderly people. American Journal of Clinical Nutrition $200275611-615$.

4 Bischoff HA, Stahelin HB, Tyndall A \& Theiler R. Relationship between muscle strength and vitamin D metabolites: are there therapeutic possibilities in the elderly? Zeitschrift für Rheumatologie 200059 (Suppl 1) 39-41.

5 Dace A, Martin-el Yazidi C, Bonne J, Planells R \& Torresani J. Calcitriol is a positive effector of adipose differentiation in the OB 17 cell line: relationship with the adipogenic action of triiodothyronine. Biochemical and Biophysical Research Communications 1997 $232771-776$.

6 Suarez F, Zeghoud F, Rossignol C, Walrant O \& Garabedian M. Association between vitamin D receptor gene polymorphism and sex-dependent growth during the first two years of life. Journal of Clinical Endocrinology and Metabolism 199782 2966-2970.

7 Keen RW, Egger P, Fall C, Major PJ, Lanchbury JS, Spector TD et al. Polymorphisms of the vitamin D receptor, infant growth, and adult bone mass. Calcified Tissue International $199760233-235$.

8 Barger-Lux MJ, Heaney RP, Hayes J, DeLuca HF, Johnson ML \& Gong G. Vitamin D receptor gene polymorphism, bone mass, 
body size, and vitamin D receptor density. Calcified Tissue International $1995 \mathbf{5 7} 161-162$.

9 Geusens P, Vandevyver C, Vanhoof J, Cassiman JJ, Boonen S \& Raus J. Quadriceps and grip strength are related to vitamin D receptor genotype in elderly nonobese women. Journal of Bone and Mineral Research 199712 2082-2088.

10 Gennari L, Becherini L, Falchetti A, Masi L, Massart F \& Brandi ML. Genetics of osteoporosis: role of steroid hormone receptor gene polymorphisms. Journal of Steroid Biochemistry and Molecular Biology 200281 1-24.

11 Ericsson M, Johansson K, Nordgren B, Nordesjo LO \& Borges O. Evaluation of a dynamometer for measurement of isometric and isokinetic torques. Uppsala Journal of Medical Sciences $1982 \mathbf{8 7}$ 223-233.

12 Grundberg E, Brändström H, Ribom LE, Ljunggren Ö, Kindmark A \& Mallmin H. A poly adenosine repeat in the human vitamin D receptor gene is associated with bone mineral density in young Swedish women. In Calcified Tissue International $2003 \mathbf{7 3}$ 455-462.

13 Houston LA, Grant SF, Reid DM \& Ralston SH. Vitamin D receptor polymorphism, bone mineral density, and osteoporotic vertebral fracture: studies in a UK population. Bone $199618249-252$.

14 Pfeifer M, Begerow B \& Minne HW. Vitamin D and muscle function. Osteoporosis International 200213 187-194.

15 Blanchet C, Giguere Y, Prud'homme D, Dumont M, Rousseau F \& Dodin S. Association of physical activity and bone: influence of vitamin D receptor genotype. Medicine and Science in Sports Exercise $20023424-31$.
16 Ye WZ, Reis AF, Dubois-Laforgue D, Bellanne-Chantelot C, Timsit J \& Velho G. Vitamin D receptor gene polymorphisms are associated with obesity in type 2 diabetic subjects with early age of onset. European Journal of Endocrinology 2001145 181-186.

17 Kamei Y, Kawada T, Kazuki R, Ono T, Kato S \& Sugimoto E. Vitamin D receptor gene expression is up-regulated by 1,25dihydroxyvitamin D3 in 3T3-L1 preadipocytes. Biochemical and Biophysical Research Communications 1993193 948-955.

18 Yamagata M, Nakajima S, Tokita A, Sakai N, Yanagihara I, Yabuta K et al. Analysis of the suitable levels of messenger RNA derived from different polymorphic alleles in the vitamin D receptor gene. Journal of Bone and Mineral Metabolism 199917 $164-170$.

19 Durrin LK, Haile RW, Ingles SA \& Coetzee GA. Vitamin D receptor 3'-untranslated region polymorphisms: lack of effect on mRNA stability. Biochimica et Biophysica Acta 19991453 311-320.

20 Carling T, Rastad J, Akerstrom G \& Westin G. Vitamin D receptor (VDR) and parathyroid hormone messenger ribonucleic acid levels correspond to polymorphic VDR alleles in human parathyroid tumors. Journal of Clinical Endocrinology and Metabolism 1998 $832255-2259$.

Received 26 August 2003

Accepted 26 November 2003 